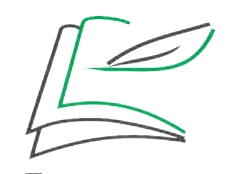

Entretextos 20(2):5-22;jul./dez. 2020

ISSN 1519-5392

DOI: $10.5433 / 1519-5392.2020 v 20 n 2 p 5$

\title{
Multiletramentos no ensino de língua inglesa: gêneros discursivos multimodais e práticas leitoras
}

\author{
Multiliteracies in the teaching of English language: multimodal discursive \\ genres and reading practices
}

\begin{abstract}
Multialfabetizaciones en la enseñanza del idioma inglés: géneros discursivos multimodales y prácticas de lectura
\end{abstract}

\author{
Kaian Lago ${ }^{1}$ (iD https://orcid.org/0000-0003-0292-6766 \\ Wesley Pinto Hoffmann ${ }^{2}$ (iD) https://orcid.org/0000-0002-5814-1573 \\ Ernani Cesar de Freitas ${ }^{3}$ (iD) https://orcid.org/0000-0002-8920-9446 \\ Luis Henrique Boaventura ${ }^{4}$ (iD) https://orcid.org/0000-0001-7760-0184
}

\begin{abstract}
RESUMO: Este estudo tem por objetivo analisar práticas de leitura necessárias para a compreensão de textos que contemplam linguagens verbo-visuais, em especial do gênero infográfico, considerando os aspectos multimodais que requerem (multi)letramentos. A questão norteadora é a seguinte: as práticas leitoras no ensino de língua inglesa precisam considerar os multiletramentos para abranger os sentidos produzidos em textos de gêneros discursivos multimodais. Baseamo-nos nas contribuições de Bakhtin (2016) sobre gêneros do discurso, nas considerações de Lemke (2010) sobre leitura, e nas de Rojo (2012) a respeito de multiletramentos e multimodalidade, além de outros referenciais. Para a análise, escolhemos um infográfico, já que promove a interação não só entre corpus e leitor, mas também entre textos e contextos, bem como significados intratextuais. A pesquisa é exploratória e bibliográfica, com abordagem qualitativa. Como resultado, reforçamos a importância dos gêneros discursivos multimodais em sala de aula, porquanto se pretende oportunizar práticas leitoras e de ensino de Língua Inglesa que prezem pelo desenvolvimento discursivo dos indivíduos.
\end{abstract}

PALAVRAS-CHAVE: Gêneros discursivos. Multiletramentos. Práticas leitoras.

\footnotetext{
${ }^{1}$ Graduado em Letras - Português/Inglês e Respectivas Literaturas pela Universidade de Passo Fundo (UPF). E-mail. kaianspricigol@gmail.com

2 Acadêmico de Letras- Português/Inglês e Respectivas Literaturas na Universidade de Passo Fundo (UPF). E-mail: 164075@upf.br

3 Doutor em Letras (PUCRS) com pós-doutorado em Linguística Aplicada e Estudos da Linguagem (PUC-SP);

Professor da Universidade de Passo Fundo e da Universidade Feevale.E-mail: nanicesar@terra.com.br

4 Doutor em Letras (UPF). Bolsista PNPD/CAPES na Universidade de Passo Fundo. E-mail:

luishboaventura@hotmail.com
} 


\begin{abstract}
The present study aims at analyzing reading practices necessary for the comprehension of texts that contemplate verbal-visual languages, especially in the infographic genre, considering the multimodal aspects that require (multi) literacy. The guiding question of this study is this: the reading practices in English language teaching need to considermultilevels to encompass the senses produce $d$ in texts of multimodal discursive genres. As the presence of these genres considered multimodal becomes more pronounced, we must recognize the importance of the study about the variability of its appropriation in the school environment. For this, we rely in particular on Bakhtin's (2016) contributions on discourse genres, on Lemke's (2010) remarks on reading, and on Rojo's (2012) remarks on multilevels and multimodality, as well as other references. To make such an analysis, we chose an infographic, since it promotes interaction not only between corpus and reader, but also between texts and contexts, as well as intratextual meanings. The present study presents exploratory and bibliographical research, with a qualitative approach. As a result, we reinforce the importance of multimodal discursive genres in the classroom, because it is intended to provide reader and teaching practices of English language that cherish the discursive development of individuals.
\end{abstract}

KEYWORDS: Discursive genres. Multiliteracies. Reading practices.

RESUMEN: El presente estudio tiene por objetivo analizar prácticas de lectura necesarias para la comprensión de textos que contemplan lenguajes verbo-visuales, en especial del género infográfico, considerando los aspectos multimodales que requieren (multi) letras. De esta forma, la cuestión orientadora de este estudio está así prevista: las prácticas lectoras en la enseñanza de lengua inglesa necesitan considerar los multiletramentos para abarcar los sentidos producidos en textos de géneros discursivos multimodales. Nosotros basamos en las contribuciones de Bakhtin (2016) sobre géneros del discurso, en las consideraciones de Lemke (2010) sobre lectura, y en las de Rojo (2012) sobre multiletramentos y multimodalidad, además de otros referenciales. Para la análisis, elegimos un infográfico, ya que promueve la interacción no sólo entre corpus y lector, sino también entre textos y contextos, así como significados intratextuales. El presente estudio presenta una investigación exploratoria y bibliográfica, con abordaje cualitativo. Como resultado, reforzamos la importancia de los géneros discursivos multimodales en el aula, por cuanto se pretende oportunizar prácticas lectoras y de enseñanza de Lengua Inglesa que prezem por el desarrollo discursivo de los individuos.

PALABRAS CLAVE: Géneros discursivos. Multialfabetizaciones. Prácticas lectoras.

\title{
Introdução
}

Até o fim do século $X X$, a construção de sentidos nas mais diversas práticas discursivas esteve atrelada à progressão linear, como consequência das modalidades analógicas, que restringiam a relação entre os diferentes gêneros discursivos. Já nas formas de comunicação atuais, em diversos meios, seja o literário, jornalístico, artístico, entre outros incontáveis, a formação dos sentidos majoritariamente acontece voltada para a multiplicidade de gêneros, de maneira a possibilitar um melhor entendimento. Em uma geração marcada por avanços tecnológicos, refletidos nos campos sociais por meio do contato entre diferentes línguas e culturas, mesclam-se o real e o virtual em 
novos meios, modificando a forma como os diferentes gêneros são apropriados para a interação social.

A leitura evolui de uma percepção única para então favorecer novas interações e construções globais de sentido que se reinventam. Com os Gêneros Multimodais, surge a necessidade de uma leitura que compreenda os diferentes gêneros discursivos em circulação e integre-os na formação dos possíveis sentidos; os multiletramentos, principalmente quando $o$ ato linguístico envolve o contato com uma cultura estrangeira. A partir deste ponto, surge a necessidade de a escola - o ambiente institucional de aprendizagem - formar sujeitos capazes de compreender os diversos gêneros envolvidos na leitura. Por isso, a questão norteadora nesse estudo é concebida da seguinte forma: as práticas leitoras no ensino de Língua Inglesa precisam considerar os multiletramentos para abranger os sentidos produzidos em textos de gêneros discursivos multimodais.

O objetivo consiste, portanto, em analisar práticas de leitura necessárias para a compreensão de textos que contemplam linguagens verbo-visuais, em especial do gênero infográfico, considerando os aspectos multimodais que requerem os multiletramentos. Ou seja, pedagogias em que o aluno consiga integrar os diferentes gêneros de maneira satisfatória dentro e fora da escola, valorizando as diferentes línguas, culturas e meios onde a leitura é realizada, refletindo sobre as práticas discursivas e propondo caminhos que possam ser utilizados nas práticas leitoras no ensino de Língua Inglesa, de modo que a leitura envolva o domínio das diversas habilidades requeridas pelas manifestações textuais da atualidade.

A fim de formarmos a proposta, dividimos nossas reflexões em três seções: na primeira das seções, "Um passo para a leitura multimidiática: letramentos sociais", discutimos a concepção de leitura e como a tecnologia influenciou essa concepção; na segunda, "Multiletramento e multimodalidade", refletimos sobre as esferas dos gêneros do discurso e discutimos os novos panoramas de leitura com os multiletramentos; por fim, a partir dessas reflexões, dedicamo-nos na terceira seção, "As práticas leitoras e de ensino", à análise do corpus selecionado, o infográfico "Evolution of music: The impact of digital on the Music Industry". Conforme a análise, refletimos sobre possíveis caminhos que possam ser usados nas práticas leitoras para que a leitura seja realizada de forma a contemplar os conceitos sugeridos na prática de ensino de Língua Inglesa. Da mesma forma destacamos, como resultado, a importância dos gêneros discursivos 
multimodais, quando se pretende oportunizar práticas leitoras e de ensino de Língua Inglesa que prezem pelo desenvolvimento discursivo dos indivíduos, apropriando-se da riqueza de significados originada pelas formas de letramento atuais.

\section{Um passo para a leitura multimidiática: letramentos sociais}

A leitura molda diferentes aspectos da sociedade desde os primeiros registros históricos de quando o ser humano passou a manifestar-se manipulando os signos linguísticos a fim de registrar momentos, histórias, descobertas, dúvidas e criações. Sem dúvida, a sincronia estabelecida entre a leitura e a escrita marca o desenvolvimento das línguas ao redor do mundo e a expansão sociocultural que hoje é tão vasta e miscigenada. Portanto, não é errôneo considerar a leitura e a escrita como fenômenos culturais, produtos de diferentes contextos baseados na interação social e desenvolvimento de gerações de indivíduos apoiados nos agrupamentos populacionais que possibilitaram o desenvolvimento das línguas.

Como defende Volóchinov (2017, p. 181), "a língua no processo de sua realização prática não pode ser separada do seu conteúdo ideológico ou cotidiano", já que "toda palavra é ideológica, assim como cada uso da língua implica mudanças ideológicas" e "a estrutura do enunciado, bem como da própria vivência expressa, é uma estrutura social" (VOLÓCHINOV, 2017, p. 217, grifo do autor). Desse modo, a interação verbal é marcada nas diferentes formas de comunicação durante a manifestação dos planos ativos da língua, como é o caso da leitura, da escrita e, por conseguinte, do letramento, no momento em que ocorre o processo enunciativo inserido no contexto social. Desse modo, "Os letramentos [...] produzem uma chave entre o eu e a sociedade: o meio através do qual agimos, participamos, e nos tornamos moldados por sistemas e redes 'ecossociais' mais amplos [...]" (LEMKE, 2010, p. 456, grifo do autor).

Os gêneros discursivos são uma espécie de reflexo da interação social. Os gêneros podem ser caracterizados conforme a capacidade do sujeito de se comunicar, a depender do seu objetivo comunicativo, visto que "a vontade discursiva do falante se realiza antes de tudo na escolha de certo gênero do discursd" (BAKHTIN, 2016, p. 3738, grifo do autor), pois os gêneros são tipos de enunciados relativamente estáveis que circulam em todas as esferas comunicativas da sociedade. $\mathrm{O}$ pensamento bakhtiniano 
provoca reflexões no que se refere aos processos de ensino/aprendizagem nas práticas leitoras em língua inglesa por levar em consideração o fazer humano na produção de discursos; segundo Bakhtin (2016, p. 38-39), "a língua materna - sua composição vocabular e sua estrutura gramatical - não chega ao nosso conhecimento a partir de dicionários e gramáticas, mas de enunciados [...]".

A escola é uma das esferas comunicativas mais importantes para o ato da comunicação, pois é o ambiente institucional responsável por oportunizar o contato com os diferentes gêneros, onde o indivíduo pode aprender a competência necessária para compreendê-los. Na grande maioria das vezes, os sujeitos falantes não percebem que toda vez que se comunicam, escolhem determinados gêneros discursivos, de acordo com seu objetivo na construção de sentidos, atribuindo a si mesmo um papel de passividade funcional. Os enunciados estão sempre se reinventando conforme as necessidades da sociedade e não podemos caracterizar os gêneros como formas fixas da língua, mas sim como formas que se adaptam, ajustando-se àquilo que os sujeitos necessitam para construir sentido em determinadas situações de enunciação, levando em consideração a realidade social onde vivem.

Em meio à multiplicidade cultural, é possível refletir sobre as manifestações linguísticas sob as quais a leitura esteve apoiada ao longo da história. Vemos que o aprimoramento das formas de comunicação esteve sempre interligado a elementos como a leitura, a escrita, o discurso oral, entre outros, por estes também pertencerem ao grande englobado das manifestações da linguagem. Dessa forma, a partir do momento em que revoluções sociais mobilizaram inovações linguísticas, inevitavelmente todos os elementos subsequentes a ela se mobilizaram por consequência. Foi o caso da explosão tecnológica que marcou o fim do século XX e o início do século XXI.

A inserção das novas tecnologias redesenhou os meios de comunicação, principalmente viabilizando novas formas de expressão e marcando o início da instantaneidade dos diálogos com as trocas de mensagens e acesso a conteúdos de forma "imediata". Peguemos como exemplo uma simples pesquisa. Até meados da década de 80, para realizar uma pesquisa, era necessário recorrer a um ou mais livros, muitas vezes deslocando-se até uma biblioteca ou espaços culturais que possibilitassem o contato do indivíduo com o material para, no fim das contas, obter uma resposta analógica e pouco específica. A internet revolucionou a comunicação porque, ao mesmo 
tempo em que possibilitou a pesquisa rápida, também possibilitou a instantaneidade da comunicação, Trata-se da primeira fase na revolução comunicativa.

A segunda fase já foi voltada a outros princípios. Podemos considerar que começou a partir da necessidade de fluidez na leitura dos materiais propiciados pela primeira fase. De nada adianta ter tanto conteúdo sem a desenvoltura funcional para acessá-lo. Desta forma, surgiu a compactação de diferentes matrizes em algo ainda mais rápido e instantâneo, Na perspectiva da multiplicidade das instâncias sociais, isto é, quando há uma maior valorização da formação de leitor, isto se manifesta à medida que ganha espaço a necessidade de um (multi)letramento que melhor contribua para a nova fase de entendimento multissemiótico.

Segundo Fiorin (2008), Bakhtin não elaborou uma obra didática pronta para ser ensinada na escola. Não há uma teoria facilmente aplicável nem uma metodologia acabada para a análise dos fatos linguísticos e literários. Todavia, isso não impede que o pensamento bakhtiniano norteie as práticas pedagógicas. Bakhtin exerceu a docência, ele faz uma reflexão revelando a dependência entre linguagem e vida; e a reflexão da experiência docente está presente na sua obra. Apesar de o filósofo não ter desenvolvido a sua teoria dos gêneros voltada, especificamente, para o trabalho pedagógico, houve uma apropriação dos seus estudos, na área da educação, para orientar os educadores no sentido de ajudar os educandos a desenvolverem suas competências e habilidades linguísticas. No Brasil, Roxane Rojo é uma autora que faz uso dos gêneros do discurso pensando no fazer pedagógico e formação dos alunos multiletrados.

Quando nos deparamos com as duas fases da revolução comunicativa, vemos que há uma forma mais complexa de apropriação das esferas constituintes no ato enunciativo. Rojo (2012) fará justamente a relação entre as propostas do reunido teórico chamado de Círculo de Bakhtin e a "transdisciplinaridade" em ascensão nos estudos discursivos como novos desafios aos letramentos ortodoxos e às teorias. "O texto contemporâneo, multissemiótico ou multimodal, envolvendo diversas linguagens, mídias e tecnologias, coloca, pois, alguns desafios para a teoria dos gêneros do discurso do Círculo" (ROJO, 2012, p. 19-20).

Os textos referidos multimodais não devem ser viabilizados como meras ramificações do signo verbo-visual. Segundo Rojo (2012, p. 19), eles são "textos compostos de muitas linguagens (ou modos, ou semioses) e que exigem capacidades e 
práticas de compreensão e produção de cada uma delas [...] para fazer significar". Dessa forma, o que antes era tratado como letramento evolui para um conceito pluralizado de "letramentos", dado o reconhecimento da multimodalidade integrada presente nos textos em circulação. Aprofundaremos a seguir com as noções de multiletramentos que imbricam a multimodalidade.

\section{Multiletramento e multimodalidade}

Que os meios de comunicação implicaram novas formas de contato com os textos, todos já sabemos. Porém, tais pressupostos levantam o enfoque dos fenômenos multimodais como fatores sociais e não apenas referentes à internalização e exteriorização mecânica dos multissignificados por parte do indivíduo. Assim, toda manifestação linguística vista do plano de expressão como evento social e discursivo seria uma manifestação ou representação multimodal, nos mostrando que a multimodalidade, embora explicitamente acentuada pela inserção das novas tecnologias de informação, sempre esteve presente nos textos escritos e orais.

Desse modo, as mais diferentes formas de manifestação de um texto como ação linguística e social implicam diferentes modalidades ou significados, de acordo com a contextura que a estiver regendo durante a expressão. Todos os textos inseridos nas tecnologias de informação, isto é, mídias, recombinam-se de muitas maneiras, criando redes de interpretação e significação infinitas. "Toda semiótica é semiótica multimídia e todo letramento é letramento multimidiático" (LEMKE, 2010, p. 456). Sob o panorama social, vemos que a intensificação da circulação de informação reflete diretamente nos modos de construir e produzir sentido por meio da leitura, escrita e transmissão de conteúdos nos diversos meios populares à sociedade.

Rojo (2012) destaca a importância do benefício das teorias Bakhtinianas referente ao "enfoque global de hibridização e reinterpretação transdisciplinar da contribuição de diferentes campos (pedagogia, semiótica, linguística aplicada, antropologia, sociologia)", de modo que a relação estabelecida entre elas favoreça o estudo dos textos, discursos e culturas. Ao nos apropriarmos de determinados gêneros do discurso estaremos, por consequência, implicando formas de letramento. "As conexões que fazemos [...] são parcialmente individuais, pois são características da 
nossa sociedade e do lugar que nela ocupamos: [...] Letramentos são sempre sociais" (LEMKE, 2010, p. 458).

De acordo com Cope e Kalantzis (2000), o termo Multiletramentos engloba a multiplicidade de canais de comunicação e mídia, juntamente com a saliência da diversidade cultural e linguística, deste modo "descrevendo" a emergência cultural, institucional e global que compõem as novas manifestações da linguagem. $O$ termo envolve modos de representação que variam de acordo com a cultura e o contexto, sendo mais amplos que apenas a língua. Kress e Van Leeuwen (2001) apresentam uma crítica ao modo como as mais diversas formas de expressão se configuravam de uma maneira muito mais limitada, cada uma com seu próprio modelo, sem qualquer espaço para diferenças. Recentemente, para os autores, essa espécie de estabilização começou a se alterar, uma vez que alguns limites foram sobrepostos, não apenas nas formas de expressão mais ousadas, como o cinema ou a música, mas também em documentos que supostamente teriam mais chances de se manterem inalteráveis, como aqueles produzidos por departamentos governamentais, universidades, entre outros.

Rojo (2012) explica que usamos práticas letradas o tempo todo, e as práticas são para a vida e requerem multiletramentos para compreenderem as diversas linguagens dos textos. Os multiletramentos não são realizados de maneira transmissiva, é preciso uma pedagogia, e alguns autores propunham alguns requisitos dos multiletramentos. Cope e Kalantzis (2000) sustentam essa reflexão a partir da discussão sobre uma pedagogia resultante de uma complexa integração de quatro fatores interpenetrados que são requisitos para o sujeito protagonista do multiletramento. Rojo (2012) explica que os fatores seriam: a) formar um usuário funcional (que tenha competência técnica e conhecimento prático); b) criador de sentidos; c) analista crítico (que entende o que é dito/estudado como fruto de seleção prévia; e d) transformador (que usa o que foi aprendido de novas formas) ${ }^{5}$.

O diagrama da pedagogia dos multiletramentos explicado por Rojo (2012) interpenetra-se e requer funcionalidade do aluno, haja vista que ele precisa saber operar o dispositivo e seus programas, como um requisito mínimo; também é preciso que seja um produtor, e para ser produtor, o aluno necessita ser um leitor crítico e com isso ser o produtor que transforma, trazendo a ideia de recriar, remixar os sentidos dos textos.

\footnotetext{
${ }^{5}$ É possível conferir os quatro fatores no "Mapa dos multiletramentos" proposto por Rojo (2012, p. 29).
} 
Essa pedagogia envolve uma "prática situada", pois se baseia, inicialmente, em práticas que fazem parte das culturas internas dos alunos (culturas populares, de massa), sendo, por conseguinte, os gêneros, mídias e outras manifestações de linguagem por eles conhecidos. Envolve "instrução aberta", que é uma análise dessas práticas, gêneros, mídias, e linguagens e de seus processos de produção e de recepção, o que se dá a partir de algo que Cope e Kalantzis (2000) determinam como um "enquadramento dos letramentos críticos que buscam interpretar os contextos sociais e culturais de circulação e produção desses designs e enunciados", tendo em vista uma prática transformadora.

Lemke (2010, p. 473) acentua essa tese ao afirmar que "a chave para os paradigmas de aprendizagem interativa, no entanto, não são nem os hiperlinks nem a multimídia, mas a interação por si mesma". Desse modo, vemos que o mais importante não é o domínio das tecnologias de comunicação, mas o processo que ele desencadeará a partir da interação do indivíduo com os diferentes enunciados por meio dessa pedagogia, de maneira que possibilite a recriação de (multi)significados aplicados, principalmente, aos diversos contextos sociais presentes no cotidiano do indivíduo. Mais uma vez vemos a importância do campo social na construção de sentidos e modalidades discursivas. A seguir, trataremos dos procedimentos metodológicos que guiarão nossa análise para, posteriormente, observarmos a aplicação de tais conceitos no corpus escolhido.

\section{Metodologia de análise}

Propomos uma discussão sobre conceitos cada vez mais pertinentes, como o Multiletramento, iniciado pelos estudos de cope e Kalantzis (2000), e a Multimodalidade, de Lemke (2010), relembrando conceitos-chave abarcados pelos Gêneros Discursivos e suas Esferas. Além disso, focamos a importância do ato da leitura no cenário educacional contemporâneo, marcado pelos avanços sociais, a partir dos estudos de Bakhtin (2016), para então relacionarmos tais teorias ao que se discute na academia atualmente, sobretudo a partir das contribuições de Rojo (2012) acerca das pedagogias de multiletramento voltadas às práticas leitoras, além de outros referenciais complementares. 
O presente estudo envolve uma pesquisa exploratória e bibliográfica com abordagem qualitativa. Nosso objetivo é analisar práticas de leitura necessárias para a compreensão de textos que contemplam linguagens verbo-visuais, em especial do gênero infográfico, considerando os aspectos multimodais que requerem os multiletramentos. Selecionamos como objeto dessa análise o infográfico "Evolution of music: The impact of digital on the Music Industry", apontando a importância das múltiplas linguagens na construção de sentidos dos gêneros discursivos multimodais projetados pelos multiletramentos. O objetivo está de acordo com a questão que norteia este trabalho: as práticas leitoras no ensino de língua inglesa devem levar em consideração os multiletramentos para abranger os sentidos produzidos em textos de gêneros discursivos multimodais, de modo a compreender os sentidos nas práticas leitoras de língua inglesa. Esse parece ser um passo incontornável no ensino de línguas para alunos que já encontram textos multimodais em seu cotidiano, de modo que a sala de aula deve aproximar-se o quanto for possível de um estado no qual o aluno se sinta à vontade e, por consequência, envolvido e curioso.

Escolhemos um infográfico a fim de promover a interação não só entre corpus e leitor, mas também entre textos e contextos, bem como significados intratextuais. Sua escolha reforça o que identificamos na pesquisa: os conhecimentos socioculturais dos alunos, bem como seu contato com múltiplas linguagens dentro e fora de sala de aula, têm um impacto positivo em sua formação como leitores multiletrados, de quem se exige uma habilidade de compreensão e comunicação em vários níveis para poder navegar em sociedade de modo hábil e competitivo.

Na sequência, partimos para a análise do corpus de pesquisa de acordo com as considerações de Bakhtin (2016), Lemke (2010) e Rojo (2012).

\section{As práticas leitoras e de ensino}

Quando falamos sobre gêneros multimodais, requeremos multiletramentos que podem ser utilizados nas práticas leitoras, no caso o gênero infográfico, que é pouco utilizado nas práticas pedagógicas de ensino de Língua Inglesa. Muitas vezes, o contato com o gênero fica restrito a outros meios que não o escolar, e os alunos acabam por não ter a oportunidade de trabalhar com um gênero verbo-visual rico em informatividade. Quando os instrumentos tecnológicos começaram a fazer parte das 
políticas governamentais e privadas de aprimoramento educacional, os estudantes aprimoraram o contato com os recursos multimidiáticos que, no caso de muitos, já estava integrado ao convívio social fora da sala de aula.

Aos poucos, a necessidade da escola de incorporar novas medidas de aprendizagem que favorecessem o uso das novas tecnologias foi crescendo. Novas políticas escolares passaram a programar a utilização dos recursos tecnológicos até o momento em que praticamente todos tivessem o seu devido espaço na educação regular. Não é novidade para ninguém que muitas escolas ainda oferecem resistência ao uso de celulares, tablets e notebooks, mas a grande maioria já é equipada com redes de informática utilizando computadores de mesa e outros recursos de uso comum e partilhado.

O maior problema, porém, consiste justamente no uso mediado dos recursos, uma vez que há um desinteresse muito presente pelos materiais analógicos, fiéis heranças da escola tradicional, bem como na realização de um letramento regular de forma a desenvolver o entendimento de textos multissemióticos. Como contemplar os recursos tecnológicos de modo a favorecer o letramento multissemiótico? De que forma isto se configura no ensino de uma língua estrangeira? Como possibilitar o contato com outras culturas apropriando-se de elementos multimodais? De primo, compreendamos 0 impacto das esferas sociais no letramento escolarizado e como ele se apresenta na perspectiva multimidiática.

Em meios a esses contextos, o gênero infográfico é extremamente relevante para a mediação do uso de interpretações textuais multimodais - atreladas às práticas de multiletramento - ao ensino de língua estrangeira, como levantado anteriormente. 0 gênero possibilita, entre outros aspectos, a interação entre textos verbais e não verbais complementando sentidos implícitos ao sujeito falante, como veremos a seguir na figura 1: 
Figura 1 - Infográfico "Evolution of Music"

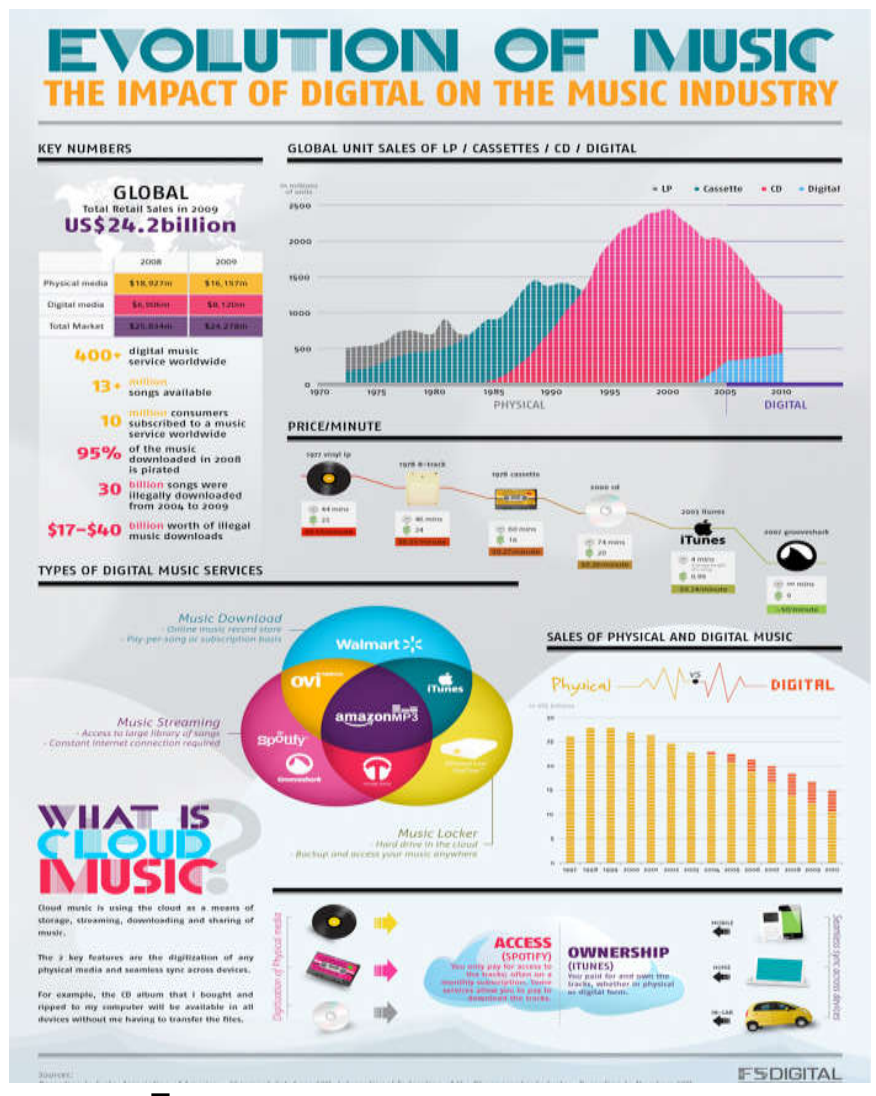

Fonte: Infographics Archive (2018).

O infográfico representa uma verdadeira conversação entre os textos verbais e não verbais, estabelecendo a tipologia do discurso verbo-visual. É possível observar que, caso o texto não verbal estivesse ausente, o sentido seria insuficiente, impossibilitando a interpretação plena do conteúdo previsto pela figura total. As imagens e representações gráficas, como os ícones, cores, números, servem de apoio semântico às construções de significação integradas ao texto verbal. Como conceitua Kress e Van Leewen (2001),

Os desenhos são as conceptualizações das formas dos produtos e eventos semióticos. Três coisas se desenham simultaneamente: (1) uma formulação de um discurso ou combinações de discursos, (2) uma (inter) ação particular [...] e (3) uma forma particular de combinar os modos semióticos. (KRESS; VAN LEEUWEN, 2001, p. 13)

As imagens complementam os textos progredindo linearmente, de modo a estabelecer contatos que ilustrem o que foi referido pelo texto, dando continuidade a ele. Lemke (2010, p. 458) defende que sempre que "construímos significado durante a leitura de um texto ou interpretação de um gráfico ou figura, nós o fazemos através da conexão dos símbolos à mão com outras imagens [...]". Isto é, a construção de 
significados partida da interpretação de um texto multimodal não é mera construção, mas ressignificação.

O contato que o indivíduo terá com esses recursos dependerá em níveis de qualidade de entendimento daquilo que está enraizado na cultura onde ele se encontra inserido e, consequentemente, aquilo que ele terá internalizado. Por esse motivo é tão importante apresentar possibilidades com diferentes gêneros na sala de aula: "quanto mais dominamos os gêneros, maior é a desenvoltura com que os empregamos e mais plena e nitidamente descobrimos neles a nossa individualidade [...]" (BAKHTIN, 2016, p. 41). Esse processo de trazer novos gêneros, Rojo (2012, p. 16) define como "descolecionar os 'monumentos' patrimoniais escolares, pela introdução de novos e outros gêneros do discurso".

O infográfico analisado contribui para o avanço da leitura multimodal a partir das noções de Lemke (2010, p. 462) de que "o texto significa mais quando justaposto à figura, e da mesma forma a figura quando colocada ao lado de um texto". A ressignificação resultante é um fator de prima importância para que haja o entendimento inicial sobre os contatos culturais e dialogismo entre sociedades e grupos sociais. Não podemos esquecer que "as formas da língua e as formas típicas dos enunciados, isto é, os gêneros do discurso, chegam à nossa experiência e à nossa consciência juntas e estreitamente vinculadas" (BAKHTIN, 2016, p. 38-39).

O contato cultural propiciado pela interpretação multimodal é o primeiro passo no reconhecimento de culturas e ideologias. O mesmo ocorre referente aos períodos históricos onde a música teve maior relevância em determinados grupos sociais ou regiões da sociedade globalizada, como é retratado em algumas partes do infográfico. O sujeito deve ser capaz de reconhecer a presença da linguagem não verbal e a sua importância durante a significação. "Devemos ajudar os alunos a compreenderem exatamente como ler o texto de forma diferente e interpretar a imagem de forma diferente, em função da presença um do outro" (LEMKE, 2010, p. 462).

Isso significa que os elementos verbais se comunicam com os não-verbais. Como a linguagem verbal está em língua estrangeira, o modo como as imagens encontram-se inseridas no texto geral definem o modo como interpretação se tornará quase plena. Em uns momentos, a imagem está atrás do texto (como no texto Key Numbers), em outros acima (como no gráfico Price/Minute). Em outros casos, como em "Types of Digital Musical Services", a relação entre texto e imagem dá-se pela adoção de gráficos, 
cuja informatividade marcam os princípios da interpretação. As imagens mais uma vez complementam o sentido do texto verbal. Além disso, a estilística das palavras remete a períodos de ascensão musical moderna (anos 60, 80), cores vivas que destacam essas características, também remetendo a figuras como discos ou placas de danceteria/estilística de álbuns. Já a disposição das cores possui significados um tanto mais complexos, definindo propriedades como as relações entre os gêneros musicais, levantamento de aspectos positivos e negativos acerca dos dados observáveis, etc. A presença de veículos para representar a indústria musical ( $C D$, disco, fita) e também sua interação com os gráficos ricos em referência - cada um de uma cor - são apresentados de maneira à realmente referenciar a diversidade dos gêneros e representá-los por meio das cores (CD/streaming/pop em alta = rosa, azul, cores vivas, já LP/Blues/estilos não tão populares na contemporaneidade = tons mais frios: cinza, azul acinzentado). Além disso, a nuvem que compõe o plano de fundo da figura provavelmente evidencia a presença majoritária das plataformas de streaming online (por nuvem) como iTunes, iCloud, além de sobpor as cores vivas dos demais elementos.

No geral, a disposição é organizada de modo a conceber a linearidade do processo de evolução da indústria musical nas últimas décadas (começando pelos dados sobre as plataformas, passando pelo comércio - venda nas mais diversas empresas e o preço médio - e terminando nas novas formas de acesso oferecidas pela nuvem). O infográfico oferece, então, uma resumida demonstração do impacto socioeconômico e cultural dessa indústria nos cenários sociais da atualidade, acentuando o público alvo da cultura de massa. Mas de quê forma toda essa informação irá auxiliar diretamente no desenvolvimento interpretativo do aluno nas aulas de Língua Inglesa? De acordo com Rojo (2009, p. 112),

[a] cultura de massa da globalização é padronizada, monofônica, homogênea e pasteurizada [...]. Por isso se tornam tão importantes hoje as maneiras de incrementar na escola e fora dela, os letramentos críticos, capazes de lidar com os textos e discursos naturalizados, neutralizados, de maneira a perceber seus valores, suas intenções, suas estratégias, seus efeitos de sentido.

É necessário que o ensino ocorra pelo letramento crítico, valorizando a diversidade cultural como atrelada à diversidade dos gêneros e formas do aluno se expressar e entrar em contato com outras culturas, outros povos, outras línguas. "Tudo 
isto requer, ao menos para professores e especialistas da mídia uma compreensão útil de semiótica multimidiática" (LEMKE, 2010, p. 462). Oferecendo multiplicidade de conteúdos semânticos e gêneros discursivos aos indivíduos, de modo a impulsionar o contato com os diferentes pontos de vista provenientes das diversas culturas, o professor estará desenvolvendo o senso crítico dos alunos para a percepção dos aspectos sociais que o permeiam como também estará aplicando de forma uniforme e certeira os princípios de um multiletramento.

A prática de leitura precisa contemplar as culturas de referência dos alunos para que tenham papel transformador na construção de sentido e transformação de textos na sociedade, e a abordagem dos multiletramentos é importante para abrir ainda mais as possibilidades que a leitura na era digital proporciona.

\section{Conclusão}

Este artigo teve como tema o modo como as práticas leitoras de língua inglesa podem incorporar os multiletramentos para ensino na escola, fazendo um debate sobre a figura do estudante na aquisição das técnicas específicas de domínio dos multiletramentos, como esse processo de aquisição tem influência da bagagem sociocultural e cognitiva e sua relação com a materialidade, interferindo de forma direta nos resultados das práticas leitoras em sala de aula, do que Lemke (2010) se apropria em suas considerações.

O nosso objetivo foi analisar as práticas de leitura necessárias para a compreensão de textos que contemplam linguagens verbo visuais, considerando os aspectos multimodais que requerem multiletramentos, especificamente no texto do gênero infográfico, verificando como ocorre o multiletramento em sala de aula, de uma maneira que o gênero não seja lido como uma complementação de sentidos por união de imagens e palavras, simplesmente.

Na elaboração da pesquisa, observamos que os conhecimentos socioculturais dos estudantes e a diversidade de linguagens presentes nos textos que circulam na sociedade influenciam positivamente na formação de um aluno multiletrado. 0 multiletramento busca um entendimento dos processos sociais a partir dos diferentes gêneros textuais em circulação, e precisa de um profissional capaz de levar em consideração as diferentes culturas, num hibridismo que a contemporaneidade provocou sem dar ênfase a uma cultura isolada. O professor precisa aproximar-se da 
realidade dos alunos e, a partir disso, desenvolver um olhar crítico dos estudantes, que não podem ser tratados como seres vazios de conhecimentos.

Não centramos nosso estudo em tentar descobrir um modo único de desenvolver os multiletramentos nas leituras dos alunos, nossa ideia era tentar descobrir como os multiletramentos se realizam, e como funciona na materialidade, que é o texto. Os multiletramentos estão ligados ao fazer social, a diversidade de linguagens e culturas ligadas na contemporaneidade, e nessa diversidade o estudante está como protagonista do processo de aprendizagem, e ao professor compete desenvolver a autonomia e o contato com diversos gêneros textuais, para assim, vivenciar uma experiência de construção dos multiletramentos em sala de aula.

As transformações da tecnologia e a consequente transformação dos gêneros que circulam no meio social não podem ser previstos de maneira exata, pois a internet vem modificando em uma velocidade muito rápida os textos e a leitura. É preciso que estejamos conectados e abertos a diferentes linguagens, interagindo e pesquisando as novas possibilidades de significação no mundo, que não param de se reinventar. Trabalhar com os multiletramentos em sala de aula é um desafio, e nosso estudo apresenta limitações: não há como prever com objetividade o resultado de uma prática leitora de língua inglesa em sala de aula, porém é possível continuar construindo saberes e dialogando, para encontrar caminhos que facilitem o aprendizado de uma língua estrangeira através dos multiletramentos na escola.

A principal contribuição desse estudo é a de reconhecer que os multiletramentos representam a complexidade das relações sociais às quais estamos diariamente expostos, em qualquer língua e cultura. É importante que haja destaque aos gêneros discursivos multimodais, quando se pretende oportunizar práticas leitoras e de ensino de língua que prezem pelo desenvolvimento discursivo dos indivíduos, apropriando-se da riqueza vasta de significados originados pelos diversos letramentos atuais. Os multiletramentos dizem respeito a todos nós enquanto indivíduos e como coletivo na sociedade marcada por processos de mudanças, em que a colaboração na elaboração dos textos nos situa num mundo tão plural de sentidos. 


\section{Referências}

BAKHTIN, Mikhail. Os gêneros do discurso. São Paulo: Editora 34, 2016.

COPE, Bill; KALANTZIS, Mary. Multiliteracies: literacy learning and the design of social futures. London: Routledge, 2000.

FIORIN, José Luíz. Introdução ao pensamento de Bakhtin. São Paulo: Ática, 2008.

INFOGRAPHICS Archive. Evolution of music: the impact of digital on the music industry. Disponível em: https://www.infographicsarchive.com/music/the-evolution-of-music. Acesso em: 20 set. 2018.

KRESS, Gunther; VAN LEEUWEN, Theo. The modes and media of contemporary communication. Londres: Hodder Education, 2001.

LEMKE, Jay L. Letramento metamidiático: transformando significados e mídias. Trabalho de Linguística Aplicada, Campinas, SP, v. 49, n. 2, p. 455-479, jul./dez. 2010.

ROJO, Roxane. Letramentos múltiplos, escola e inclusão social. São Paulo: Parábola Editorial, 2009.

ROJO, Roxane. Pedagogia dos multiletramentos: diversidade cultural e de linguagens na escola. In: ROJO, Roxane; MOURA, Eduardo (org.). Multiletramentos na escola. São Paulo: Parábola Editorial, 2012. p. 11-31.

VOLÓCHINOV, Valentin. Marxismo e filosofia da linguagem. São Paulo: Editora 34, 2017. 